\title{
PHOSPHORYLATION OF NONHISTONE CHROMOSOMAL PROTEINS EARLY DURING THE PREREPLICATIVE PHASE OF THE CELL CYCLE OF WI-38 HUMAN DIPLOID FIBROBLASTS
}

\author{
D.E. PUMO ${ }^{1}$, G.S. STEIN ${ }^{2}$ and L.J. KLEINSMITH ${ }^{1}$ \\ 1 Division of Biological Sciences, University of Michigan, Ann Arbor, Mich. 48109 , \\ and $^{2}$ Department of Biochemistry, University of Florida, Gainesville, Fla. 32610, U.S.A.
}

Accepted 10 December, 1975

Stimulation of confluent monolayers of nondividing WI-38 cells to proliferate is accompanied by a doubling in the rate of phosphorylation of nonhistone chromosomal proteins during the first hour. The use of cycloheximide to inhibit protein synthesis does not appear to affect phosphorylation of the nonhistones. Nondividing and serum-stimulated cells exhibit qualitative differences in the phosphorylation and dephosphorylation of individual polypeptide peaks resolved by polyacrylamide gel electrophoresis. These results are consistent with other evidence implicating nonhistone protein phosphorylation as an early event involved in the activation of transcription occurring during cell proliferation.

When confluent monolayers of nondividing WI-38 human diploid fibroblasts are stimulated to proliferate by replacing exhausted growth medium with fresh medium containing fetal calf serum, activation of transcription occurs within one hour (Rovera et al., 1973; Farber et al., 1971, 1972). This early activation of DNA-dependent RNA synthesis during the pre-replicate phase of the cell cycle is reflected in intact cells by a two-fold increase in uridine incorporation into RNA (Weber, 1972), and in vitro by a similar increase in the template activity of isolated chromatin or nuclei (Farber et al., 1972; Tsai et al., 1973; Bombik et al., 1974). During this period nonhistone proteins undergo marked changes in synthesis and association with the genome, suggesting that these polypeptides may play a key role in stimulating the readout of genetic information (Tsuboi et al., 1972; Rovera et al., $1971,1973)$. More direct evidence that nonhistone chromosomal proteins function in such a regulatory capacity comes from the observation that the template activity of chromatin reconstituted with nonhistone chromosomal proteins obtained from fibroblasts $1 \mathrm{~h}$ following stimulation is higher than the template activity of chromatin reconstituted with nonhistone chromosomal proteins from nondividing cells (Stein et al., 1972).

Several lines of evidence implicate phosphorylation of nonhistone chromosomal proteins as being important in the activation of repressed gene loci in general (reviewed in Kleinsmith, 1974; Stein et al., 1974; Kleinsmith, 1975) and specifically during defined periods of the cell cycle (Platz et al., 
1973; Karn et al., 1974). To further elucidate the possible involvement of nonhistone chromosomal proteins in the regulation of cell proliferation, we have examined the changes which occur in the phosphorylation of these proteins during the first hour following stimulation of WI-38 human diploid fibroblasts to divide.

\section{MATERIALS AND METHODS}

\section{Cell culture}

WI-38 human diploid fibroblasts were grown in monolayer culture in Eagle's basal medium (BME) containing 10\% fetal calf serum. The cells were incubated in a moist $\mathrm{CO}_{2}$ incubator. Seven days after plating 11 blake culture flasks the cells were confluent, and cellular proliferation was stimulated by discarding the exhausted growth medium and replacing it with fresh BME containing $20 \%$ fetal calf serum.

The WI-38 human diploid fibroblasts utilized in these studies ranged from passage 26 to 28 . This is a significant consideration in as much as age-dependent modifications in the metabolism of chromosomal proteins and the stability of their mRNAs have been observed in late-passage human diploid cells (Stein et al., 1975).

\section{Labeling with radioisotopes}

In the experiments using labeled thymidine and uridine, $\left[{ }^{3} \mathrm{H}\right]$ thymidine $(1$ $\mu \mathrm{Ci} / \mathrm{ml})$ or $\left[{ }^{3} \mathrm{H}\right]$ uridine $(5 \mu \mathrm{Ci} / \mathrm{ml})$ was added to the growth medium and the cells were incubated $60 \mathrm{~min}$ at $37^{\circ} \mathrm{C}$. In the ${ }^{32} \mathrm{P}$-labeling experiments cells were incubated at $37^{\circ} \mathrm{C}$ for $30 \mathrm{~min}$ in $20 \mathrm{ml}$ of phosphate-free $\mathrm{BME}$ containing ${ }^{32} \mathrm{P}(100-300 \mu \mathrm{Ci} / \mathrm{ml})$ and $2 \%$ fetal calf serum. Following the incubations, labeling medium was discarded and all monolayers were washed twice with $25 \mathrm{ml}$ of warm $\left(37^{\circ} \mathrm{C}\right)$ serum-free BME (containing phosphate). The growth medium was then either replaced (pulse-chase experiments), or cells were harvested (pulse-labeling experiments). Each sample consisted of $4 \times 10^{8}$ cells. Isotope was obtained from New England Nuclear Corporation, Boston, Massachusetts.

\section{Isolation of nuclei}

Preparation of nuclei was carried out at $4^{\circ} \mathrm{C}$. Cells were harvested by scraping with a rubber policeman, washed three times with Earle's balanced salt solution, and lysed with $80 \mathrm{mM} \mathrm{NaCl}-20 \mathrm{mM}$ EDTA-1\% Triton X-100 ( $\mathrm{pH} 7.2$ ). Nuclei were pelleted by centrifugation at $1000 \mathrm{~g}$ for $4 \mathrm{~min}$ and were washed three times with lysing medium. This was followed by two washes with $0.15 \mathrm{M} \mathrm{NaCl}-0.01 \mathrm{M}$ Tris ( $\mathrm{pH}$ 8.0). Nuclei isolated in this manner are free of cytoplasmic contamination when examined by phase-contrast microscopy. 
Nuclear pellets were suspended in 10 volumes of $0.14 \mathrm{M} \mathrm{NaCl}$, followed by an equal volume of $2.0 \mathrm{M} \mathrm{NaCl}-0.03 \mathrm{M}$ Tris $(\mathrm{pH} \mathrm{7.5)}$. The sample was disrupted in a polytron homogenizer (Brinkman) for $20 \mathrm{sec}$ at 72 volts. Following homogenization, 1.5 volumes $0.02 \mathrm{M}$ Tris, $\mathrm{pH} 7.5$ was added; $70 \%$ was added slowly, continuously stirring with a glass rod, while the remainder was added quickly, also with stirring. After gel formation, samples were spun in a swinging bucket rotor at $95,000 \mathrm{~g}$ for $60 \mathrm{~min}$. The resulting supernatant was dialysed overnight in $0.1 \%$ SDS-0.1\% 2-mercaptoethanol-0.01 $\mathrm{M}$ sodium phosphate buffer ( $\mathrm{pH} 7.0$ ). The dialysed protein was concentrated four to six fold in cellulose bags using either Bio-Gel P-200 or sucrose as a dehydrating agent. Following concentration, samples were redialysed in the SBS-mercaptoethanol-phosphate buffer.

\section{Polyacrylamide gel electrophoresis}

SDS-polyacrylamide gels (10\%) made according to the procedure of Weber et al. (1969) were sliced into $1.0 \mathrm{~mm}$ slices. ${ }^{32} \mathrm{P}$-containing gels were counted in toluene scintillation fluid. ${ }^{3} \mathrm{H}$-containing gels were first hydrolysed in 0.2 $\mathrm{ml}$ of $30 \% \mathrm{H}_{2} \mathrm{O}_{2}$ at $37^{\circ} \mathrm{C}$ overnight, then counted in Triton $\mathrm{X}-100$ toluene scintillation fluid.

\section{RESULTS AND DISCUSSION}

Because of the use of ${ }^{32} \mathrm{P}$ as a label for protein phosphorylation in these experiments, it was necessary to first determine whether significant amounts of labeled RNA or DNA are present in our nonhistone protein fraction. As is shown in Fig. 1, none of the nonhistone protein peaks separated by polyacrylamide gel electrophoresis is labeled with $\left[{ }^{3} \mathrm{H}\right]$ uridine, indicating the absence of significant contamination by RNA. However, incorporation of $\left[{ }^{3} \mathrm{H}\right]$ thymidine into peak 1 and, to a lesser extent, peak 2 , indicates the presence of DNA in the high-molecular-weight region of the gel. Further tests with pronase, RNase, and DNase (data not shown) confirm the results obtained with $\left[{ }^{3} \mathrm{H}\right]$ labeling experiments, indicating that only peak 1 contains significant amounts of ${ }^{32} \mathrm{P}$ in material other than protein.

Fig. 2 illustrates the relationship between the ${ }^{32} \mathrm{P}$ profile and the Coomassie Blue staining bands of the nonhistone chromatin protein fraction. Note the almost total absence of stain in the peak 1 area of the gel. Experiments are currently being performed in our laboratory to further delineate the the character of peak 1 , but it certainly does not contain, in any significant amount, phosphorylated nonhistone chromatin proteins (data not shown). Therefore, peak 1 will not be discussed further in this paper.

The rates of nonhistone chromosomal protein phosphorylation were compared in nondividing WI-38 cells and WI-38 cells $1 \mathrm{~h}$ following stimulation to 


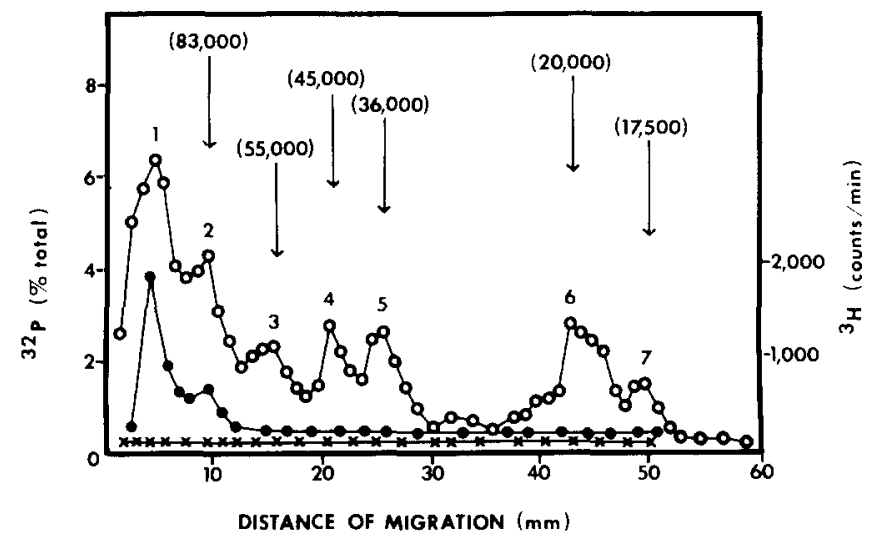

Fig. 1. Polyacrylamide gel electrophoretic fractionation of nonhistone chromosomal phosphoproteins labeled for $30 \mathrm{~min}$ with ${ }^{32} \mathbf{P}\left({ }_{-}-\right),\left[{ }^{3} \mathrm{H}\right]$ thymidine $(\bullet-\bullet)$ and $\left[{ }^{3} \mathrm{H}\right]$ uridine $(X-X)$. The numbers in parentheses are estimated molecular weights.

proliferate. Cells were pulse-labeled with ${ }^{32} \mathrm{P}$ in the presence or absence of cycloheximide $(5 \mu \mathrm{g} / \mathrm{ml})$ for $30 \mathrm{~min}$ and the specific activities of the nonhistone chromosomal proteins were determined (Table I). An average 2.1-fold increase in the incorporation of ${ }^{32} \mathrm{P}$ into nonhistone chromosomal proteins is apparent in the serum-stimulated cells. Since no significant differences were observed in the acid-soluble phosphate pools of nondividing and serum-stim-

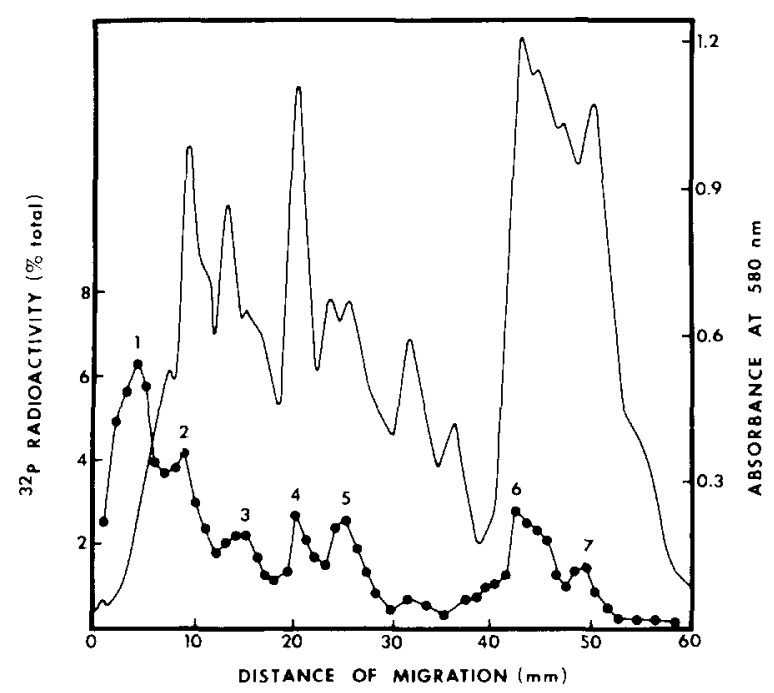

Fig. 2. Polyacrylamide gel electrophoretic fractionation of nonhistone chromosomal proteins labeled for $30 \mathrm{~min}$ with ${ }^{32} \mathrm{P}(\bullet-)$ ) and stained with Coomassie Blue (- - 
TABLE I

Comparison of phosphorylation (as $\mathrm{cpm}{ }^{32} \mathrm{P} / \mathrm{mg}$ protein) of nonhistone chromatin phosphoprotein fraction from nondividing and serum-stimulated cells. The differences in $\mathrm{cpm} /$ mg protein from experiment to experiment are due to differences in amount of isotope employed.

\begin{tabular}{llrl} 
& Nondividing & Serum-stimulated & Ratio ${ }^{\text {a }}$ \\
\hline Expt. 1 & 835,800 & $2,090,000$ & 2.50 \\
Expt. 2 & 407,000 & 840,200 & 2.06 \\
Expt. 3 b & 688,000 & $1,184,000$ & 1.72 \\
\hline
\end{tabular}

a Ratio of cpm of stimulated cells to nondividing cells.

b Cells were exposed to cycloheximide $(5 \mu \mathrm{g} / \mathrm{ml})$ during the ${ }^{32} \mathrm{P}$-labeling period.

ulated WI-38 cells (data not shown), the observed difference in isotope incorporation probably reflects an increased rate of nonhistone chromosomal protein phosphorylation. In as much as isotope incorporation was assayed in the presence of an inhibitor of protein synthesis, it is reasonable to conclude that ${ }^{32} \mathrm{P}$ incorporation is a valid indicator of the rate of phosphorylation of pre-existing rather than newly synthesized nonhistone chromosomal proteins. However, it is also conceivable that the increased rate of isotope incorporation into the nonhistone chromosomal proteins may, at least in part, be accounted for by an enhanced rate of association of phosphorylated cytoplasmic or nucleoplasmic proteins with the genome. Exchanges of nonhistone chromosomal proteins between the genome and other cellular compartments, particularly the nucleoplasm, have been reported (Stein et al., 1973).

We then wished to determine whether there is a selective phosphorylation of defined molecular weight classses of nonhistone chromosomal proteins 1 $\mathrm{h}$ following stimulation of WI-38 cells to proliferate. Cells were pulse-labeled with ${ }^{32} \mathrm{P}$ for $30 \mathrm{~min}$, and nonhistone chromosomal polypeptides were isolated and fractionated electrophoretically according to molecular weight on SDS-polyacrylamide gels (Fig. 3). The most striking and reproducible effect in stimulated cells is the enhanced phosphorylation of nonhistone chromosomal proteins which migrate in the 20,000 dalton region of the gels (peak 6). This increased phosphorylation is refractory to cycloheximide at a concentration $(5 \mu \mathrm{g} / \mathrm{ml})$ which inhibits nuclear protein synthesis by $96 \%$, indicating that it represents phosphorylation of pre-existing nonhistone chromosomal proteins. Since the increased phosphorylation of peak 6 occurs in cells stimulated to proliferate in the presence of cycloheximide and actinomycin D (1 $\mu \mathrm{g} / \mathrm{ml}$, which inhibits RNA synthesis by $98 \%$ ), it appears that the selective phosphorylation of these nonhistone chromosomal proteins occurs in the absence of RNA synthesis. It is puzzling to note, however, that an increase in the phosphorylation of peak 6 sometimes also occurs in nondividing cells treated with cycloheximide (Fig. $3 \mathrm{~B}$ ). One can speculate that this may result 


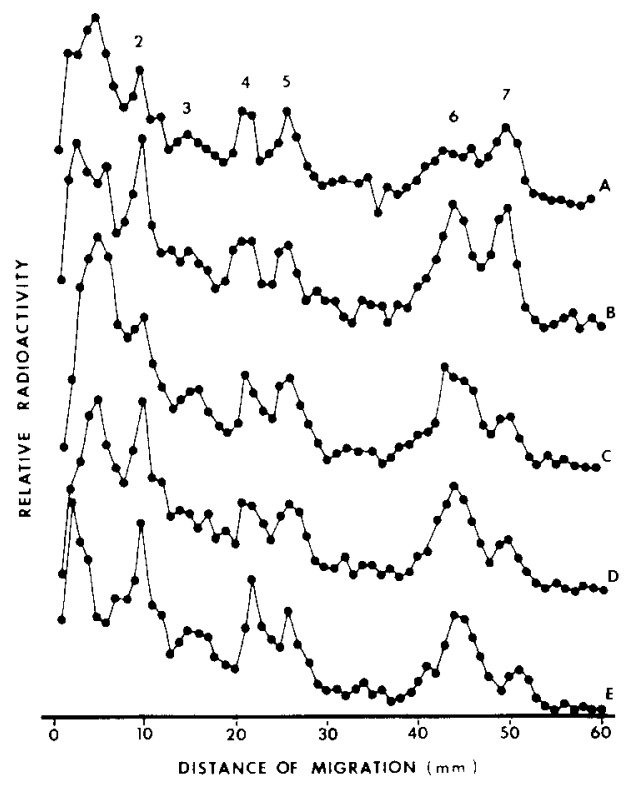

Fig. 3. Polyacrylamide gel electrophoretic fractionation of nonhistone chromosomal phosphoproteins labeled for $30 \mathrm{~min}$ with ${ }^{32} \mathrm{P}_{\mathrm{i}}$ : A) nondividing control; B) nondividing treated with cycloheximide $(5 \mu \mathrm{g} / \mathrm{ml})$; C) $1 \mathrm{~h}$ following $20 \%$ serum-stimulation; D) $1 \mathrm{~h}$ following serum-stimulation - treated with cycloheximide $(5 \mu \mathrm{g} / \mathrm{ml})$; and $\mathbf{E}) 1 \mathrm{~h}$ following serum-stimulation in the presence of cycloheximide and actinomycin $D$.

from blocking the synthesis of a short-lived protein kinase inhibitor which normally depresses the phosphorylation of peak 6 polypeptides. If this hypothesis turns out to be correct, a similar release from inhibition may be responsible for the enhanced peak 6 phosphorylation occurring in cells stimulated to divide.

To further define modifications in the metabolism of phosphate groups on nonhistone chromosomal proteins occurring in WI-38 human diploid fibroblasts following stimulation to proliferate, phosphate turnover rates were examined. Nondividing cells were pulse-labeled with ${ }^{32} \mathrm{P}$ in the presence of cycloheximide $(5 \mu \mathrm{g} / \mathrm{ml})$ for $30 \mathrm{~min}$. Cells were then either incubated in their previous growth medium, or stimulated to proliferate by incubation in fresh growth medium containing $20 \%$ calf serum. The level of labeled phosphate in the various molecular weight classes of nonhistone chromosomal proteins was then assayed during the $4 \mathrm{~h}$ following termination of labeling. Fig. 4 is a histogram of the phosphorylation profile after $4 \mathrm{~h}$. Peak 1 has been eliminated for previously mentioned reasons. The amount of ${ }^{32} \mathrm{P}$ radioactivity after $4 \mathrm{~h}$ of 'chase' in the serum-stimulated cells, in all cases, very close to the value of ${ }^{32} \mathrm{P}$ radioactivity in the cell immediately after the removal of the isotope from the medium. A small (less than 20\%) net turnover 


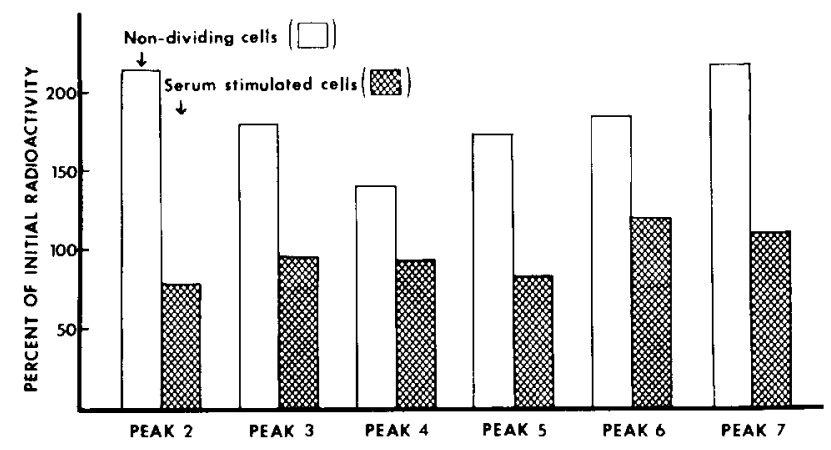

Fig. 4. Turnover, given in terms of percent of initial radioactivity, of various molecular weight classes of nonhistone chromosomal phosphoproteins in nondividing WI-38 cells and in W1-38 cells following serum-stimulation. Confluent monolayers were labeled for 30 min with ${ }^{32} \mathrm{P}_{\mathrm{i}}$ and then 'chased' for $4 \mathrm{~h}$ in the presence of their previous growth medium or stimulated to proliferate by addition of fresh medium containing $20 \%$ fetal calf serum. The nonhistone chromosomal proteins were fractionated electrophoretically as in Fig. 1, and the radioactivity in each molecular weight fraction was determined.

is evident in peaks 2 and 5 . In contrast, the nondividing cells radically increase in amount of ${ }^{32} \mathrm{P}$ radioactivity over the $4 \mathrm{~h}$ 'chase' period. Peaks 2 and 7 show increases of over $100 \%$ of the initial values. Peak 4 shows the least increase, which is still $40 \%$ higher than the initial value.

There are several possible explanations for the increase in ${ }^{32} \mathrm{P}$-radioactivity associated with nonhistone chromosomal proteins of nondividing cells $4 \mathrm{~h}$ following pulse-labeling. The intracellular pool of radioactive phosphate may remain high enough to promote additional labeling, and some radioactive phosphate groups may even be selectively transferred between phosphorylated extra-chromosomal and chromosomal macromolecules. A differential exchange of phosphorylated proteins between the genome and other cellular compartments may also be occurring. This latter phenomenon might provide an explanation as to why some nonhistone proteins accumulate more radioactivity during pulse-chase conditions than others.

The major implications of the present studies center on two findings. 1) There is roughly a 2-fold increase in phosphorylation of nonhistone chromosomal proteins in serum-stimulated cells as compared with nondividing cells, with some indication of a selective enhancement in the phosphorylation of certain polypeptides. 2) After a 4-h 'chase' the amount of ${ }^{32} \mathrm{P}$-radioactivity in the serum-stimulated cells has not changed significantly, while the amount of radioactivity in the nondividing cells has markedly increased. Taken together, these findings point to the conclusion that nonhistone chromatin proteins in serum-stimulated cells are more rapidly phosphorylated and dephosphorylated than in quiescent cells. The fact that nonhistone proteins in the nondividing cells are decidedly less active in terms of uptake and turn- 
over of ${ }^{32} \mathrm{P}$ suggests that storage of phosphorylated nonhistones may occur during the nondividing state.

Functional significance to the observed increase in phosphorylation and dephosphorylation of nonhistone proteins can be implied by taking the following into consideration. The activation of transcription early during the prereplicative phase of the cell cycle has been directly shown to be mediated by nonhistone chromosomal proteins (Stein et al., 1972); in the present studies, an increased phosphorylation and dephosphorylation of nonhistone proteins has been found to be cotemporal with this activation of RNA synthesis. Furthermore, there exists a strong correlation between variations in the phosphorylation of nonhistone chromosomal proteins and modifications in the expression of genetic information in general, and in specific during the cell cycle (Platz et al., 1973; Karn et al., 1974; Stein et al., 1974; Kleinsmith, $1974,1975)$. One can therefore speculate that phosphorylation of nonhistone chromosomal proteins plays a key role in the enhancement of transcription which accompanies the stimulation of WI-38 cells to proliferate - perhaps by rendering defined regions of the genome available for RNA synthesis.

\section{ACKNOWLEDGEMENTS}

Supported in part by grants BMS74-23418 and GB38349 from the National Science Foundation, GM20535 from the National Institutes of Health, a Guggenheim Fellowship to L.J.K., and an Elsa U. Pardee Fellowship to D.E.P.

\section{REFERENCES}

Bombik, B.M. and R. Beserga: Proc. Nat. Acad. Sci. U.S.A. 71, 2038-2042 (1974).

Farber, J., G. Rovera and R. Baserga: Biochem. J. 122, 189-195 (1971).

Farber, J., G. Rovera and R. Baserga: Biochem. Biophys. Res. Comm. 49, 558-562 (1972).

Karn, J., E.M. Johnson, G. Vidali and V.G. Allfrey: J. Biol. Chem. 249, 667-677 (1974). Kleinsmith, L.J. In: Acidic Proteins of the Nucleus, eds. I. L. Cameron and J.R. Jeter Jr. (Academic Press, New York) pp. 103-135 (1974).

Kleinsmith, L.J.: J. Cell. Physiol. 85, 459-476 (1975).

Platz, R.D., G.S. Stein and L.J. Kleinsmith: Biochem. Biophys. Res. Comm. 51, 735-740 (1973).

Rovera, G. and R. Baserga: J. Cell Physiol. 77, 201-212 (1971).

Rovera, G. and R. Baserga: Exp. Cell Res. 78, 118-126 (1973).

Stein, G.S. and D.L. Burtner: Biochim. Biophys. Acta 390, 56-68 (1975).

Stein, G.S., S. Chaudhuri and R. Baserga: J. Biol. Chem. 247, 3918-3922 (1972).

Stein, G.S., T.C. Spelsberg and L.J. Kleinsmith: Science 183, 817-824 (1974).

Stein, G.S. and C.L. Thrall: FEBS Lett. $32,41-44$ (1973).

Tsai, R.L. and H. Green: Nature New Biol. 243, 168-170 (1973).

Tsuboi, A. and R. Baserga: J. Cell Physiol. 80, 107-118 (1972).

Weber, M.J.: Nature New Biol. 235, 58-60 (1972).

Weber, K. and M. Osborn, J. Biol. Chem. 244, 4406-4412 (1969). 